\title{
Hormonal effects of drosperinone and ethinyl estradiol based combined oral contraceptives on polycystic ovarian syndrome
}

\author{
Madhusmita S. Nayak*, Deepa D. Kala, Amit Agarwal
}

Department of Obstetrics and Gynecology, Terna Medical College, Nerul-West, Navi Mumbai, Maharashtra, India

Received: 23 March 2021

Revised: 15 April 2021

Accepted: 16 April 2021

\section{*Correspondence:}

Dr. Madhusmita S. Nayak,

E-mail: drmsnayak@outlook.com

Copyright: (c) the author(s), publisher and licensee Medip Academy. This is an open-access article distributed under the terms of the Creative Commons Attribution Non-Commercial License, which permits unrestricted non-commercial use, distribution, and reproduction in any medium, provided the original work is properly cited.

\begin{abstract}
Background: Polycystic ovarian syndrome (PCOS) is a common endocrine disorder treated with combined oral contraceptives (COCs). The androgenic potential of any type of $\mathrm{COC}$ is in part determined by the progestin present. A newer form of progestin, drospirenone, has been recently introduced, and is available in combination with ethinyl estradiol.

Methods: The study was conducted on 60 patients fulfilling inclusion criteria, in the department of obstetrics and gynecology, Terna Medical College and Hospital. Patients were diagnosed as PCOS according to Rotterdam criteria. After initial evaluation, blood samples were sent for levels of serum luteinizing hormone (LH), follicle stimulating hormone (FSH), dehydroepiandrosterone-sulphate (DHEA-S), free testosterone, sex hormone binding globulin (SHBG). Each patient was advised to take a combination of $\mathrm{EE}(30 \mathrm{mcg})+$ drosperinone $(3 \mathrm{mg}), 1$ tablet daily from the second day of her menstruation for 21 days then a 7 days gap and again for 21 days and so on cyclically for 3 cycles, then to repeat the tests as done at the beginning. Hirsutism was assessed clinically using the Ferriman-Gallwey scale at initial visit and three months later.

Results: We found a significant improvement in the Serum LH, FSH levels and a significant fall in free testosterone levels accompanied by a rise in SHBG levels. There is also overall improvement in the hirsutism scores.

Conclusions: Drosperinone based COCs are a good and effective means of treatment of PCOS. Treatment duration of three months was found to be effective in our study.
\end{abstract}

Keywords: PCOS, Drosperinone, Hirsutism

\section{INTRODUCTION}

Polycystic ovary syndrome has an extremely heterogenous clinical picture and is multifactorial in etiology. It is a syndrome of ovarian dysfunction that is characterized by anovulation, usually presenting as oligomenorrhea or amenorrhea, and either clinical or biochemical hyperandrogenism and/or the presence of polycystic ovary (PCO) morphology. Clinical hyperandrogenism can lead to hirsutism, oligo-amenorrhea, acne, and alopecia.

PCOS affects $5 \%$ to $10 \%$ of women of reproductive age. ${ }^{1}$ Combined oral contraceptives (COCs) are a common treatment for PCOS. The type of COC to be used is based on 3 main variables: the type of estrogenic compound in the pill, the type of progestin used, and the dosage of the combined pill.

Estrogen component of COC is responsible for increasing circulating levels of sex hormone binding globulin (SHBG) by liver. ${ }^{2}$ The androgenic potential of any type of $\mathrm{COC}$ is in part determined by the progestin present in the pill, and the progestin's effect on SHBG.

Studies have shown that combining the same dose ethinyl estradiol (EE) with different progesterone compounds resulted in significantly different levels of SHBG. ${ }^{2,3}$ 
A newer form of progestin, drospirenone, has been recently introduced, and is available in combination with EE which acts to suppress gonadotropins. Drospirenone differs from other progestins currently available in other COC compounds, as it exhibits both antimineralocorticoid effects and anti-androgenic effects.

The aim and objective of this study was to determine correlation of hormonal changes; serum luteinizing hormone (LH), follicle stimulating hormone (FSH), dehydroepiandrosterone-sulphate (DHEA-S), free testosterone, sex hormone binding globulin (SHBG) in PCOS after 3 cycles of ethinyl estradiol + drosperinone (EE+DRSP) containing COCs.

\section{METHODS}

The Study on 'hormonal effects of drosperinone and ethinyl estradiol based COC on PCOS' - a prospective observational study was conducted on 60 patients aged between 18-30 years, attending out-patient clinics, in the department of obstetrics and gynaecology, Terna Medical College and Hospital, Navi Mumbai, after obtaining adequate written consent. Prior to commencing the study, the approval of the Institutional Ethics Committee of Terna Medical College was obtained vide letter no. TMCHRC/Surg/2018/Protocol-04/13 dated March 06, 2018. The duration of the study was for 6 months starting from April 2018 till September 2018, during which patient enrollment was done during the first 3 months and they were followed up for the next 3 months.

Sample size of 60 was obtained based on average OPD attendance of PCOS patients and patients were selected by convenience sampling technique.

\section{Inclusion criteria}

All women with PCOS (age range: 18-30 yrs) attending our out-patient services; should have spontaneous onset of puberty and normal sexual development; Should be euthyroid and normoprolactinemic.

PCOS is diagnosed on the basis of Rotterdam criteria:

(a) Clinical findings (presence of amenorrhea or oligomenorrhea, hirsutism, acne). (b) Hyperandrogenism (clinical or biochemical as raised serum testosterone or dehydroepi-androstenedione levels).

(c) Presence of bilaterally normal or enlarged ovaries (volume $>10 \mathrm{cc}$ ) containing at least 10-12 follicles on USG.

\section{Exclusion criteria}

Patients having significant liver or renal impairment. Patients having neoplasms, cardiovascular disease, unstable mental illness or any other systemic illness. Patients who have had high blood pressure, stroke, gallbladder disease, undiagnosed uterine bleeding, epilepsy, sickle cell disease, smokers, prior to elective surgery, certain types of migraine headaches. Patients with diabetes, thyroid dysfunction, congenital adrenal hyperplasia and hyperprolactinemia, hyperandrogenism other than PCOS and history of any hormonal medication.

Data was collected using pre-designed study proforma. After initial clinical and laboratory evaluation, blood samples were sent for evaluation of levels of serum luteinizing hormone (LH), follicle stimulating hormone (FSH), dehydroepiandrosterone-sulphate (DHEA-S), free testosterone, sex hormone binding globulin (SHBG). Each patient was advised to take a combination of EE $(30 \mathrm{mcg})$ + Drosperinone ( $3 \mathrm{mg}), 1$ tablet daily from the second day of her menstruation for 21 days then a 7 days gap and again for 21 days and so on cyclically. Each patient was advised to continue the tablet for 3 cycles, then to repeat the tests as done at the beginning. Patient was clinically evaluated at the first follow-up visit (after 1 month) at the out-patient clinic to rule out any side effects. The final review was performed with another set of the same tests and clinical assessments after 3 months of treatment at the second follow-up visit. Hirsutism was assessed clinically using the Ferriman-Gallwey scale at initial visit and three months later at end of treatment cycle.

Data was subjected to statistical analysis using descriptive statistics, ' $\mathrm{T}$ ' test and Chi square test

\section{RESULTS}

All 60 participants completed the treatment duration of 3 cycles without any significant adverse events. Our findings and statistical analysis are tabulated in Table 1 below.

Table 1: Findings before and after treatment.

\begin{tabular}{|c|c|c|c|c|c|c|c|}
\hline Parameters & Test & $\mathbf{N}$ & Mean & SD & $\begin{array}{l}\text { Paired T } \\
\text { test }\end{array}$ & P value & $\begin{array}{l}\text { Significant at } \\
5 \% \text { level }\end{array}$ \\
\hline \multirow{2}{*}{ FSH (IU/ml) } & Pre-test & 60 & 5.2183 & 0.6721 & $11.374 * *$ & $<0.001$ & Yes \\
\hline & Post-test & 60 & 4.8133 & 0.7505 & & & \\
\hline \multirow{2}{*}{ LH (IU/ml) } & Pre-test & 60 & 13.0583 & 1.5198 & $34.409 * *$ & $<0.001$ & Yes \\
\hline & Post-test & 60 & 7.5400 & 0.8216 & & & \\
\hline \multirow{2}{*}{ DHEA-S ( $\mu \mathrm{g} / \mathrm{dl})$} & Pre-test & 60 & 108.953 & 14.8476 & 0.269 & 0.789 & No \\
\hline & Post-test & 60 & 108.4817 & 21.4198 & & & \\
\hline
\end{tabular}




\begin{tabular}{|c|c|c|c|c|c|c|c|}
\hline Parameters & Test & $\mathbf{N}$ & Mean & SD & $\begin{array}{l}\text { Paired T } \\
\text { test }\end{array}$ & P value & $\begin{array}{l}\text { Significant at } \\
5 \% \text { level }\end{array}$ \\
\hline \multirow{2}{*}{$\begin{array}{l}\text { Free testosterone } \\
(\mathrm{pg} / \mathrm{ml})\end{array}$} & Pre-test & 60 & 9.4967 & 3.7255 & $14.259 * *$ & $<0.001$ & Yes \\
\hline & Post-test & 60 & 3.4667 & 1.0189 & & & \\
\hline \multirow{2}{*}{ SHBG ( $\mu \mathrm{g} / \mathrm{dl})$} & Pre-test & 60 & 1.6833 & 0.6580 & $10.212 * *$ & $<0.001$ & Yes \\
\hline & Post-test & 60 & 2.2183 & 0.6331 & & & \\
\hline \multirow{2}{*}{ Hirsutism score } & Pre-test & 60 & 12.3833 & 3.6411 & $5.918 * *$ & $<0.001$ & Yes \\
\hline & Post-test & 60 & 11.8667 & 3.3520 & & & \\
\hline
\end{tabular}

**Statistically highly significant at $0.01 \%$ level i.e., $\mathrm{p}<0.001$.

In our study involving 60 patients of PCOS, the mean FSH level at initiation of study was $5.2183 \mathrm{IU} / \mathrm{ml}$ with a SD of 0.6721 . At the end of study period, the mean FSH was $4.8133 \mathrm{IU} / \mathrm{ml}$ with SD of 0.7505 . This fall in $\mathrm{FSH}$ is statistically significant with $\mathrm{p}$ value $<0.001$.

The mean LH level at study initiation was $13.0583 \mathrm{IU} / \mathrm{ml}$ with SD 1.5198. At end of study, mean LH was 7.5400 IU/ml with SD 0.8216. This fall was significant with a $\mathrm{p}$ value $<0.001$.

Similar results were obtained by Guido et al in their 2004 study. ${ }^{4}$ This is because of central inhibition of gonadotrophin release by all EE/ DRSP similar to other estrogen-progesterone combination drugs. ${ }^{5}$ Also, drosperinone seems to possess a strong anti-gonadotrophic activity per se as shown by previous studies on animal models showing a fall in LH levels using DRSP alone.,

The mean DHEA-S level, at the beginning of treatment, was $108.9533 \mu \mathrm{g} / \mathrm{dl}$ with SD 14.8476 and at the end of treatment, was mean 108.4817 with SD 21.4198. This change is not considered significant.

The mean free-testosterone level at initiation was 9.4967 $\mathrm{pg} / \mathrm{ml}$ with SD 3.7255. At the end of 3 months of therapy, the mean was 3.4667 with SD 1.0189. This fall is statistically significant. This is probably because EE/ DRSP has been shown to directly reduce testosterone production by ovaries by inhibiting steroidogenic enzymes. $^{8}$

The mean SHBG level at the start of therapy was 1.6833 $\mu \mathrm{g} / \mathrm{dl}$ with SD 0.6580 while at the end of 3 months was mean $2.2183 \mu \mathrm{g} / \mathrm{dl}$ with SD 0.6331. This rise in SHBG is significant with a $\mathrm{p}$ value $<0.001$. Similar results are obtained by Guido et al and Palep-Singh et al., ${ }^{4,9}$

In our study, the mean hirsutism score at the start of treatment was 12.3833 with SD 3.6411 which fell to mean of 11.8667 with SD 3.3520 at end of 3 months treatment. This is a significant fall which can be explained by the fall in testosterone levels along with the intrinsic antiandrogenic activity. ${ }^{10}$

\section{DISCUSSION}

Drospirenone, in conjunction with EE, acts to suppress gonadotropins and thus causes inhibition of ovulation.
COCs can lead to a decrease in circulating albumin levels, leading to a decrease in dehydroepiandrosterone sulphate (DHEAS), which is strongly bound to albumin and androgen production and a decrease in peripheral androgen production through an inhibition of $5 \alpha$ reductase in the skin and a subsequent decrease in dihydrotestosterone levels. ${ }^{11-13}$ The ultimate effect is an overall decrease in gonadotropins and resulting androgens, which is the goal of PCOS treatment. In addition, the estrogen component of COC increases SHBG production by the liver, which in turn reduces the circulating levels of free testosterone and its bioavailability. ${ }^{2}$ The androgenic potential of any type of COC is in part determined by the progestin present in the pill, and the progestin's effect on SHBG. Studies done by Wiegratz and colleagues and van der Vange et al have shown that combining the same dose EE with different progesterone compounds resulted in significantly different levels of SHBG., ${ }^{2,3}$ Guido also noted a significant increase in SHBG at the $3^{\text {rd }}$ cycle, $6^{\text {th }}$ cycle, and $12^{\text {th }}$ cycle. ${ }^{4}$ Hence, the increase in SHBG occurs soon after the administration of the drospirenone-containing $\mathrm{COC}$ and that it is a long-lasting rather than transient effect. Guido's results also supported the significant decrease in testosterone found by both Pehlianov and Mitkov, and De Leo and colleagues. ${ }^{14,15}$

\section{CONCLUSION}

PCOS is a relatively common disorder in females and is troublesome due to its intrinsic hormonal changes and hyperandrogenic features. In our study, 60 patients of PCOS took a drosperinone+ehinyl estadiol based COC pill for 3 months and were reviewed. We found a significant improvement in the serum LH, FSH levels. There was a significant fall in free testosterone levels accompanied by a rise in SHBG levels. There is also an overall improvement in the hirsutism scores.

Drosperinone based COCs are a good and effective means of treatment of PCOS. No significant side effects were noticed and treatment duration of three months was found to be effective in our study.

\section{ACKNOWLEDGMENTS}

Authors are thankful to Mr. Abhiram Behera, Department of Preventive and Social Medicine, Terna Medical College, for his assistance in statistical analysis. 
Funding: No funding sources

Conflict of interest: None declared

Ethical approval: The study was approved by the Institutional Ethics Committee

\section{REFERENCES}

1. Li L, Yang D, Chen X, Chen Y, Feng S, Wang L. Clinical and metabolic features of polycystic ovary syndrome. Int J Gynaecol Obstet. 2007;97(2):129-34.

2. Wiegratz I, Kutschera E, Lee JH, Moore C, Mellinger $\mathrm{U}$, Winkler UH, et al. Effect of four different oral contraceptives on various sex hormones and serumbinding globulins. Contraception. 2003;67(1):25-32.

3. Vange N, Blankenstein MA, Kloosterboer HJ, Haspels AA, Thijssen JH. Effects of seven low-dose combined oral contraceptives on sex hormone binding globulin, corticosteroid binding globulin, total and free testosterone. Contraception. 1990;41(4):345-52.

4. Selvaggi L, Apa R, Lanzone A. Drospirenone for the treatment of hirsute women with polycystic ovary syndrome: a clinical, endocrinological, metabolic pilot study. J Clin Endocrinol Metab. 2004;89(6):2817-23.

5. Givens JR, Andersen RN, Wiser WL, Fish SA. Dynamics of suppression and recovery of plasma FSH, LH, androstenedione and testosterone in polycystic ovarian disease using an oral contraceptive. J Clin Endocrinol Metab. 1974;38(5):727-35.

6. Muhn P, Krattenmacher R, Beier S, Elger W, Schillinger E. Drospirenone: a novel progestogen with antimineralocorticoid and antiandrogenic activity. Pharmacological characterization in animal models. Contraception. 1995;51(2):99-110.

7. Muhn P, Fuhrmann U, Fritzemeier KH, Krattenmacher R, Schillinger E. Drospirenone: a novel progestogen with antimineralocorticoid and antiandrogenic activity. Ann N Y Acad Sci. 1995;761:311-35.
8. Krattenmacher R. Drospirenone: pharmacology and pharmacokinetics of a unique progestogen. Contraception. 200062(1):29-38.

9. Singh PM, Mook K, Barth J, Balen A. An observational study of Yasmin in the management of women with polycystic ovary syndrome. J Fam Plann Reprod Health Care. 2004;30(3):163-5.

10. Fuhrmann U, Krattenmacher R, Slater EP, Fritzemeier $\mathrm{KH}$. The novel progestin drospirenone and its natural counterpart progesterone: biochemical profile and antiandrogenic potential. Contraception. 1996;54(4):243-51.

11. Carlström K, Karlsson R, Von Schoultz B. Diurnal rhythm and effects of oral contraceptives on serum dehydroepiandrosterone sulfate (DHEAS) are related to alterations in serum albumin rather than to changes in adrenocortical steroid secretion. Scand J Clin Lab Invest. 2002;62(5):361-8.

12. Vrbíková J, Cibula D. Combined oral contraceptives in the treatment of polycystic ovary syndrome. Hum Reprod Update. 2005;11(3):277-91.

13. Cassidenti DL, Paulson RJ, Serafini P, Stanczyk FZ, Lobo RA. Effects of sex steroids on skin 5 alphareductase activity in vitro. Obstet Gynecol. 1991;78(1):103-7.

14. Pehlivanov B, Mitkov M. Efficacy of an oral contraceptive containing drospirenone in the treatment of women with polycystic ovary syndrome. Eur J Contracept Reprod Health Care. 2007;12(1):305.

15. De LV, Morgante G, Piomboni P, Musacchio MC, Petraglia F, Cianci A. Evaluation of effects of an oral contraceptive containing ethinylestradiol combined with drospirenone on adrenal steroidogenesis in hyperandrogenic women with polycystic ovary syndrome. Fertil Steril. 2007;88(1):113-7.

Cite this article as: Nayak MS, Kala DD, Agarwal A. Hormonal effects of drosperinone and ethinyl estradiol based combined oral contraceptives on polycystic ovarian syndrome. Int J Reprod Contracept Obstet Gynecol 2021;10:1824-7. 